\title{
An Experimental Study on the Way Bottom Widening of Pier Foundations Affects Seismic Resistance
}

\author{
Takashi Nagao \\ Research Center for Urban Safety and Security \\ Kobe University \\ Kobe City, Japan \\ nagao@people.kobe-u.ac.jp
}

\begin{abstract}
The resistance of a pier to horizontal loads, like seismic loads, is due to the flexural rigidity of its foundations and the horizontal subgrade reaction. In the event of a massive earthquake, the latter becomes very small because of the softening of the ground, while the structure may experience a large inertia force and lateral spreading pressure. Therefore, structures with high seismic resistance are required in areas with high seismicity. When a wide caisson is used as a pier foundation, a rotational resistance moment caused by the vertical subgrade reaction acting on the foundation bottom can be expected. Although this rotational resistance moment increases if the foundation is widened, in design practice the subgrade reaction coefficient is evaluated as being low under such circumstances. Therefore, even if the foundation is widened, the rotational resistance moment does not increase greatly. Rotational resistance commensurate with the increased construction cost due to foundation widening cannot be expected. In the present study, horizontal loading experiments were performed at one pier with a normal foundation and at one with widened at the bottom foundation, and the way that the widening affected the seismic performance was examined. The results show that compared with the normal foundation, the bottom-widened one experienced far less displacement and offered higher earthquake resistance.
\end{abstract}

Keywords-earthquake resistance; subgrade reaction; pier; displacement

\section{INTRODUCTION}

A pier supports vertical loads (e.g. dead weight, cargo) by means of columnar foundations (e.g. piles) that penetrate to the bedrock, and resists horizontal loads (e.g. inertia forces during an earthquake) by means of (i) the flexural rigidity of the foundations and (ii) the horizontal Subgrade Reaction (SR). As ships have become bigger, so wharfs have had to be made deeper, and this increase in water depth results in increased seismic load. In addition, it has been noted that (i) lateral spreading pressure may act during a massive earthquake and (ii) the maximum lateral spreading pressure may exceed the one specified in seismic design codes [1]. Many damages to pile foundations during the 1995 Kobe Earthquake have been reported [2], and a pier in Kobe port buckled at points below the ground surface, which was caused by the lateral spreading pressure [3]. Many other cases have been reported of wharfs being displaced laterally during earthquakes [4-7]. Because a pier is strongly affected by ground deformation during an Corresponding author: Takashi Nagao earthquake and experiences residual deformation even when its structural members are not damaged [8], the deformation performance of a pier against seismic loads is an important design criterion. The damage to the pile foundation becomes even greater when liquefaction occurs [9].

Pier foundations comprise steel-pipe and reinforcedconcrete piles, and large-diameter caissons are also used when large earthquake loads are considered. When caissons are used as foundations, a Rotational Resistance Moment (RRM) due to the vertical SR acting on the foundation base bottom is expected because of the wide foundations. In the event of a massive earthquake, the horizontal SR becomes very small because of the deterioration in ground stiffness [10]. However, because the foundations are embedded in a strong soil layer, the effect of lowered ground stiffness at the Foundation Bottom (FB) is small even during a massive earthquake, and a sufficient vertical SR can be expected. In addition, when caisson foundations are used, the area subjected to the vertical SR can conceivably be increased by widening the FB, thereby increasing the RRM to enhance the earthquake resistance. Also, the seismic performance can be expected to increase because of the soil weight acting on the widened section. However, it has been noted that although the RRM increases as the foundations are widened, the SR coefficient used in the calculation of SR decreases with increasing foundation width [11-15]. In design practice, formulas for calculating the SR coefficient are used, which incorporate that effect [16]. When such formulas are used, the RRM does not increase greatly even if the foundations are widened, and therefore one cannot expect a rotational resistance that is commensurate with the increased construction cost due to the foundation widening. However, no studies to date have clarified the effect by experiments on the frame structure, and it is very important in the earthquake-resistant design of piers to examine how the foundation width affects the earthquake resistance.

In the present study, experiments involving horizontal loading were performed on pier models with either a normal columnar foundation or one with widened FB, and how the latter affected the seismic performance was examined. Also the differences in SR and displacement performance due to the widened FB are discussed. 


\section{METHOD}

\section{A. Experiments Outline}

In the experiments, a soil tank of $900 \mathrm{~mm}$ (width) $\times 500 \mathrm{~mm}$ (depth) was used as shown in Figure 1, and a steel rigid frame model simulating a pier was installed in the ground as shown in Figure 2. This pier model was loaded horizontally using a mega-torque motor. To avoid effects due to the soil being restrained by the side walls of the soil tank, the $150 \mathrm{~mm}$-deep pier model was installed in the central part of the $500 \mathrm{~mm}$-deep soil tank. Steady braces were installed so that the horizontally elongated model would not tilt in the depth direction of the soil tank because of loading. Figure 3 shows the specifications of the model. The normal type involves a rigid frame that has a columnar foundation with a circular cross section of $60 \mathrm{~mm}$ diameter whereas the widened type involves a column that has the same diameter but whose base has been widened to $115 \mathrm{~mm}$. The dimensions of these models are based on a scaling factor (prototype/model) of 100 for the length considering the recent increases in wharf water depth. The normal and widened model weights are $0.142 \mathrm{kN}$ and $0.150 \mathrm{kN}$ respectively, the latter being heavier because it has a wider base.

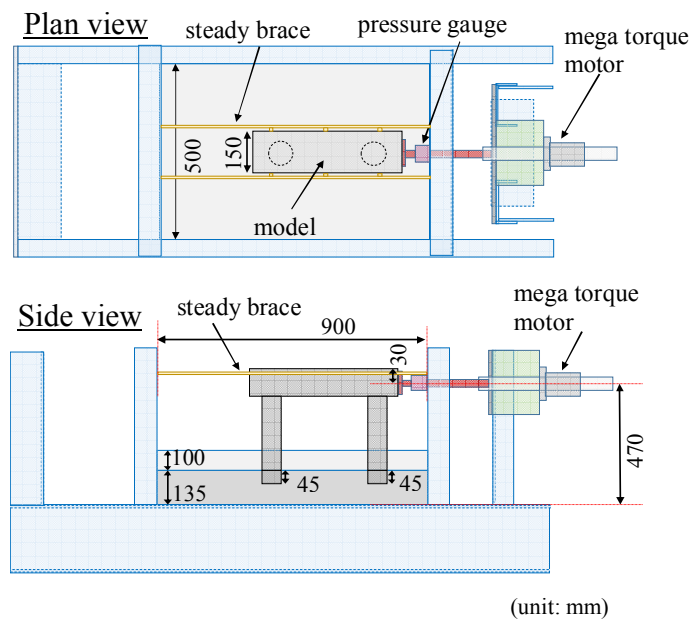

Fig. 1. Experimental soil tank

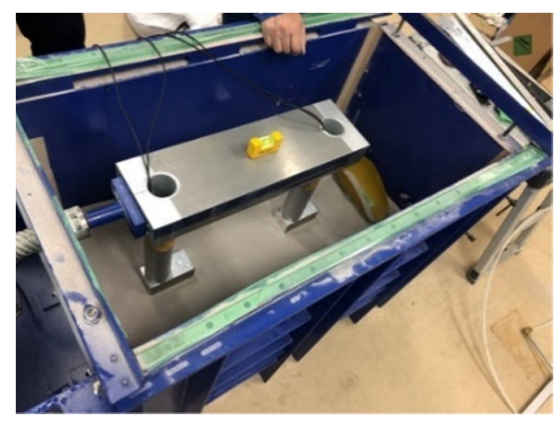

Fig. 2. Model installation status

The ground was prepared by air pluviation, using Tohoku silica sand No. 6 in the dry state. Although pier foundations penetrate solid ground, the ground shallower than the bearing stratum is usually soft. Thus the model ground comprised an upper layer and a lower layer with relative densities of $42 \%$ and $77 \%$ respectively, corresponding to standard penetration test $N$-values of 5 and 33, respectively. The upper layer was $100 \mathrm{~mm}$ thick and the lower layer was $135 \mathrm{~mm}$ thick, thereby ensuring that the deformation in the lower soil layer was not constrained because of the rigid bottom plate of the soil tank. As shown in Figure 1, the model foundation was embedded by $45 \mathrm{~mm}$ into the stronger lower layer.

(a)

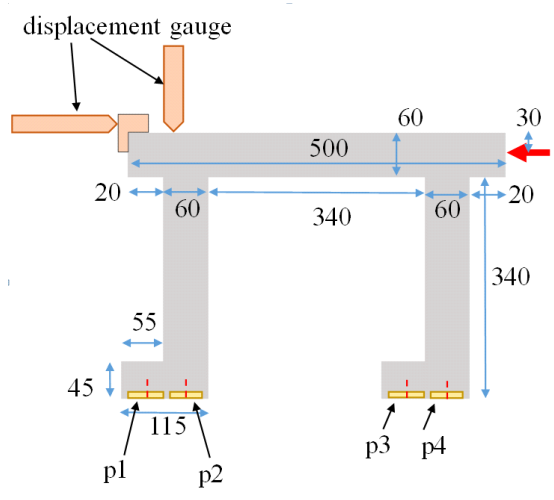

(b)

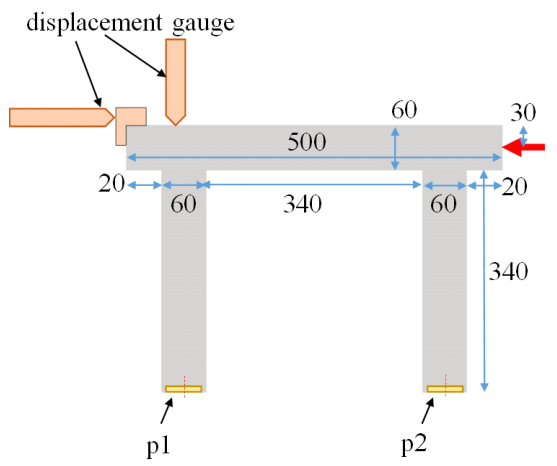

Fig. 3. Model specifications. (a) widened, (b) normal (unit: mm)

By similitude [17], the horizontal loading rate on the model was determined to be $1 / 31.6$ of the actual scale, in which the horizontal loading rate was $20 \mathrm{~cm} / \mathrm{s}$ as in [1]. The maximum displacement under loading was $10 \mathrm{~mm}$, which by similitude corresponds to an actual displacement of $10 \mathrm{~m}$.

\section{B. Measured Quantities}

The quantities measured in these experiments were the SR on the pier bottom, the horizontal and vertical displacements of the pier, and the horizontal load. Time history data were recorded by a data logger. The SR on the FB was measured by installing earth pressure gauges on the model FB, two per leg in the widened type and one per leg in the normal type, on the basis of the relationship between the diameter of the earth pressure gauge and that of the model foundations. The horizontal and vertical displacements were measured by attaching a displacement gauge to the model as shown in Figure 3. In the following, the loading side is referred to as the rear side, and the side where displacement occurs by loading is referred to as the front side. The measured data were subjected to (i) a Fast Fourier Transform, (ii) low-pass filtering at $1 \mathrm{~Hz}$, and then (iii) an inverse Fast Fourier Transform to obtain smooth time history data as in [1]. 


\section{RESULTS}

\section{A. Load-Displacement Relationship}

Figure 4 shows the time history of horizontal load (red) and horizontal displacement (blue). Because the loading was carried out at constant displacement speed, the horizontal displacement increased linearly with time at the same rate for each type. The load increased over time, but the degree of increase was not constant. In both types, the load increase with time was large until around 1s when it became gradual. This was due to the change in the displacement mode of the pier around 1s: at first the rigid frame tilted because of the horizontal load, then, as the tilt increased, the horizontal resistance was reduced by the rear side leg floating up, whereupon sliding occurred. The final horizontal displacement was $10 \mathrm{~mm}$ for both types, but the loads required to produce the final displacement differed, with the maximum load being $0.40 \mathrm{kN}$ for the widened type and $0.34 \mathrm{kN}$ for the normal type. The widened type was less likely to deform than was the normal type.

(a)
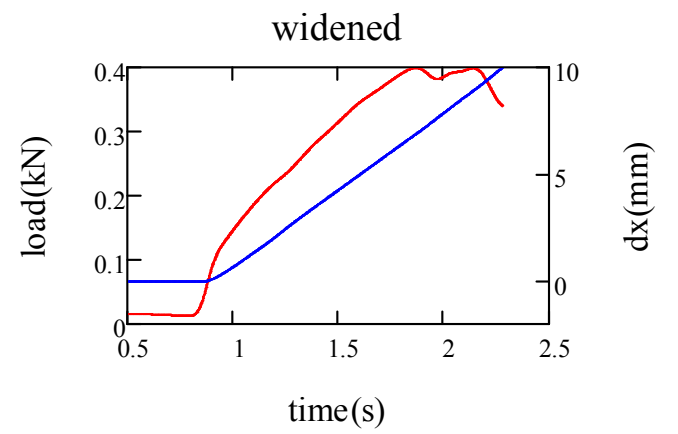

(b)

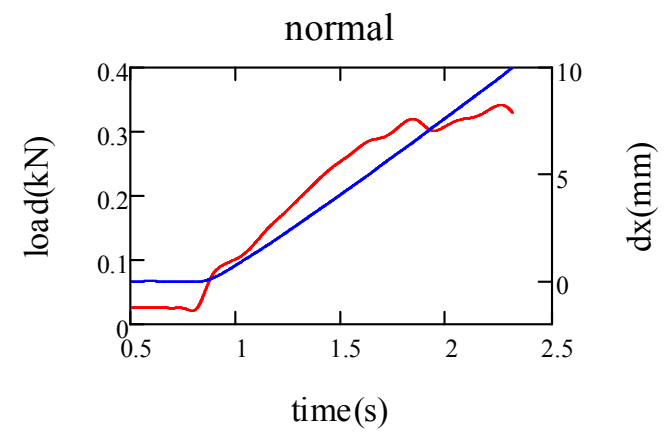

Fig. 4. Time history of horizontal load and horizontal displacement

The relationship between the horizontal displacement $(\mathrm{dx})$ and the vertical displacement (dy) is shown in Figure 5. The red line indicates the widened type and the blue line denotes the normal type. The vertical displacement is positive upward, and when the tilting occurs by horizontal loading, the model is displaced upward by rotation. A large vertical displacement occurred with horizontal displacement for the normal type, but the vertical displacement of the widened type was small. This occurred because it was difficult for the widened type to tilt because the RRM due to the vertical SR acting on the FB was large.

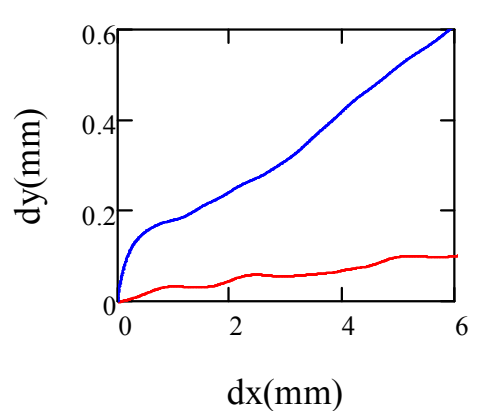

Fig. 5. Relationship between horizontal and vertical displacement

\section{B. Vertical Subgrade Reaction}

Figure 6 shows the time history of the vertical SR on the FB. As described above, the widened type had two earth pressure gauges per leg, namely $\mathrm{p} 1-\mathrm{p} 4$ from front to rear. The normal type had one earth pressure gauge per leg, namely $\mathrm{p} 1$ in the front and p2 in the rear. In both types, the SR at the rear leg decreased sharply with increasing load: it became zero and the rear leg floated upon application of a horizontal load of $0.113 \mathrm{kN}$ in the widened type and $0.091 \mathrm{kN}$ in the normal type.

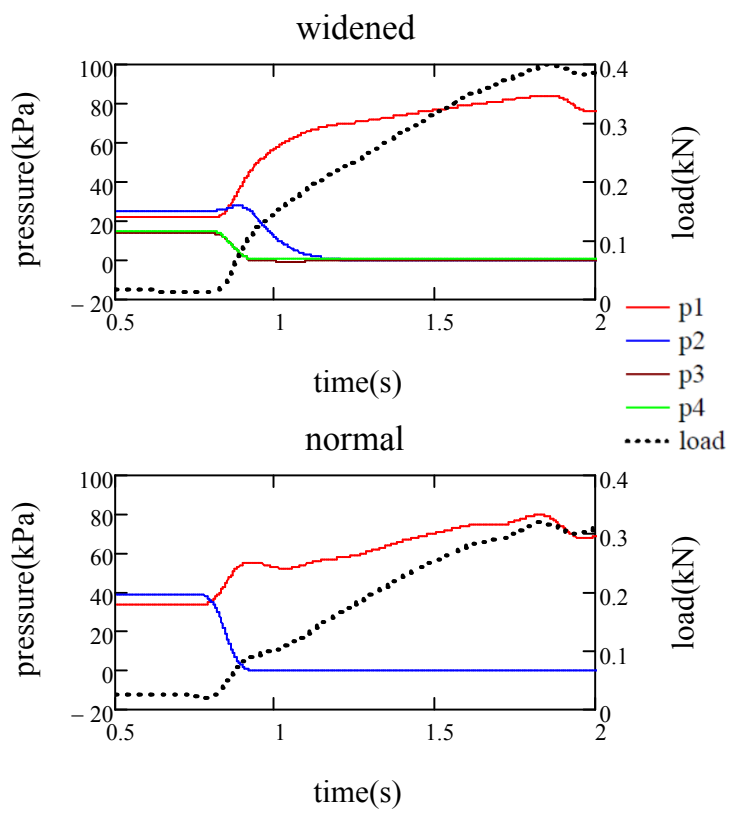

Fig. 6. Time history of SR

As a ratio to the dead weight, this load was 0.75 for the widened type and 0.64 for the normal type. The SR for $\mathrm{p} 2$ of the widened type, which was the rear side SR in the front leg, became zero when a horizontal load of $0.252 \mathrm{kN}$ was applied, which corresponded to 1.80 as a ratio to the dead weight. The front SR for $\mathrm{p} 1$ of the normal type did not increase significantly even if the load or displacement increased after the rear SR for p2 became zero. This was because the displacement mode changed from tilting to sliding. The widened type exhibited a similar tendency. 


\section{DISCUSSION}

\section{A. Vertical Subgrade Reaction Characteristics}

When a rigid frame is subjected to horizontal loading, tilted displacement occurs first. We discuss how the tilted displacement characteristics differ between the normal type and the widened type. Figure 7 shows the change in the distribution of the SR with the change in the applied load. The horizontal axis is the distance from the front end, and the stars mark the installation positions of the earth pressure gauges. The values in the legend are those of the horizontal load. When the load is small $(0.02 \mathrm{kN})$, the SR $(\mathrm{p} 2, \mathrm{p} 4)$ at the rear side of each leg is larger than that at the front side $(\mathrm{p} 1, \mathrm{p} 3)$ for both the front and rear side legs of the widened type. This occurs because in the widened type, the column is installed on the rear side rather than in the center of the base bottom, and the loading distribution of its dead weight is not uniform. Although the front side SR (p1) increases with increasing horizontal load, there is no change in the rear side SR (p2) on the front side leg in the range of horizontal load up to $0.10 \mathrm{kN}$. By contrast, the SR decreases on both rear sides (p3 and p4).

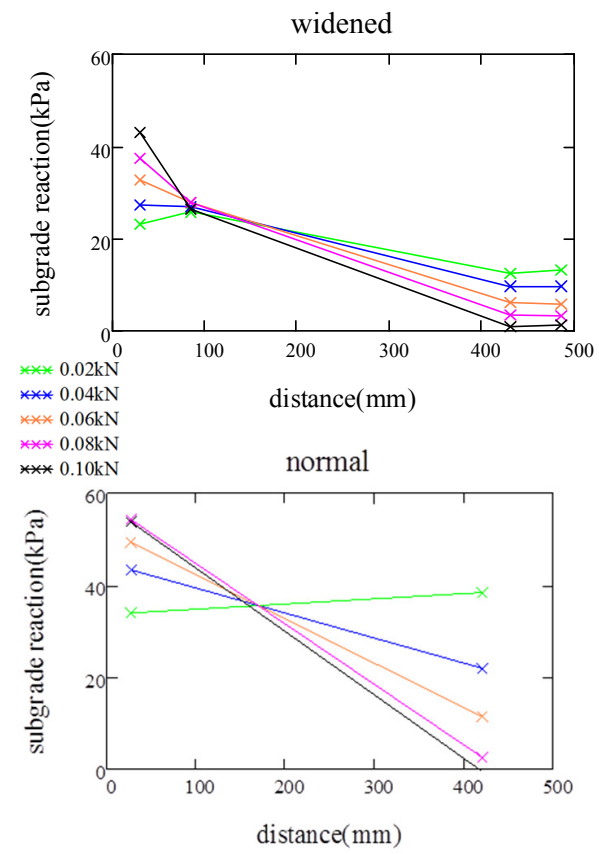

Fig. 7. Distribution of SR

In the normal type, the SR (p1) at the front increases with increasing loading and the SR (p2) at the rear decreases, but the $\mathrm{p} 2$ decrease is larger than the $\mathrm{p} 1$ increase. This is because the rigid frame does not rotate at the center of the span of the superstructure but does rotate at a point closer to the front than the center. By contrast, in the widened type, it is difficult to evaluate the rotational center in this state because the initial distribution of the dead weight is not uniform. Therefore, we first averaged the initial values of the four SRs from p1 to p4 and then subtracted their initial average values from the values of each SR. In addition, the values of the SRs on the front and back side of each leg were averaged, and were plotted against the center of the earth pressure gauge installation position for each leg. The results are shown in Figure 8, where the legend is the same as in Figure 7. These results indicate that the rotational center is unchanged and constant regardless of the magnitude of the load, and that the rotational center position differs between the normal type and the widened type. In the widened type, the rotational center is close to the center of the superstructure span, namely at 0.47 times the span length from the front end, while in the normal type, the rotational center is at 0.37 times the span length from the front end. The arm length of the RRM is larger for the widened type than for the normal type, and therefore the RRM of the widened type is larger than that of the normal type. This is the effect of bottom widening.

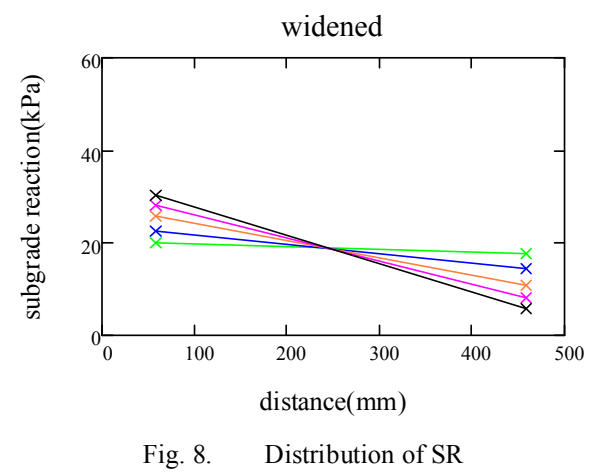

The RRM calculation is based on the SR distribution and the rotational center. The RRM values are plotted against the load in Figure 9. The red line indicates the widened type and the blue line expresses the normal type. For a load of $0.1 \mathrm{kN}$, the $\mathrm{RRM}$ is $0.045 \mathrm{kN} \cdot \mathrm{m}$ in the widened type and $0.035 \mathrm{kN} \cdot \mathrm{m}$ in the normal type, with the former being 1.28 times the latter. In design practice, SR distributions are calculated assuming that the foundation center of each leg is the rotational center when evaluating the seismic resistance of a pier. The SR distributions in such a conventional design differ greatly from the SR distributions revealed by this study, and the conventional design underestimates RRM of a pier as a frame structure because the arm length of RRM is evaluated as being short.

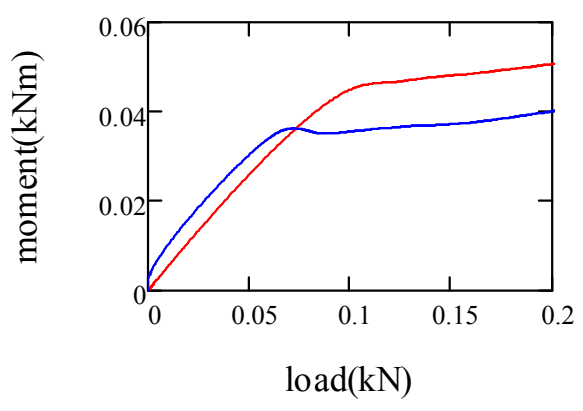

Fig. 9. Rotational resistance moment

\section{B. Displacement Characteristics}

Figure 10 compares the relationship between the loads and the horizontal displacement of the two types. The red line 
indicates the widened type and the blue line the normal type. For a given load, the widened type exhibits smaller horizontal displacement than the normal type. Because the model weights differ between the normal and the widened type, as described above, the results of comparing the displacement characteristics in seismic coefficient form by dividing the horizontal load by the model weight are converted into values on the real scale according to the similitude [17] as shown in Figure 10(b). The red line denotes the widened type and the blue line indicates the normal type. In the range of seismic coefficient of 0.4-0.6, the range of displacement ratio is $0.19-0.38$, and the larger the seismic coefficient, the higher the seismic resistance of the widened type. In comparison with the RRM ratio, the difference between the two types is large for the horizontal displacement. Therefore, the widened type can be said to have especially high horizontal displacement resistance. For vertical displacement, as shown in Figure 11, the widened type (red) produces very little displacement in comparison with the normal type (blue). In the range of seismic coefficient up to 0.6 , the displacement ratio is less than $2 \%$.

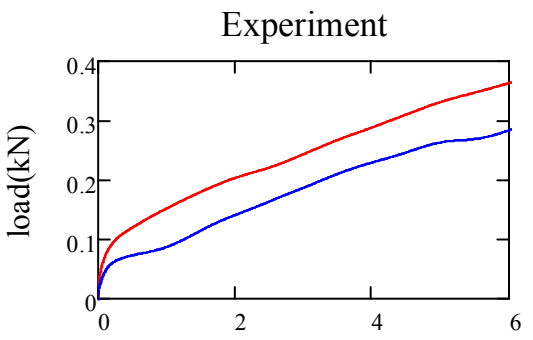

horizontal displacement(mm)

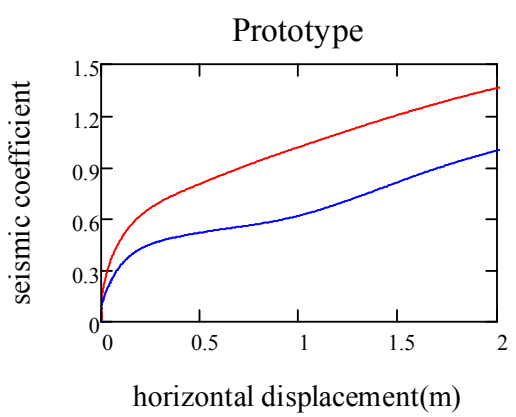

Fig. 10. Relationship between seismic coefficient and horizontal displacement

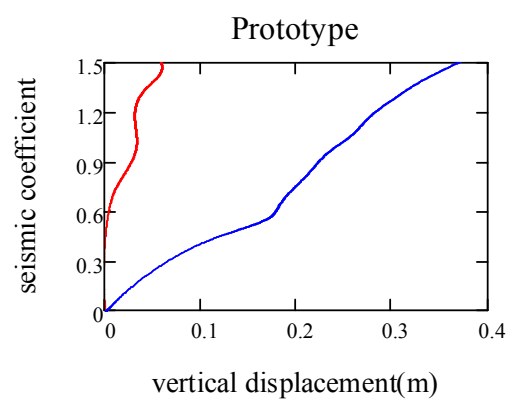

Fig. 11. Relationship between seismic coefficient and vertical displacement

\section{CONCLUSIONS}

In this study, in order to discuss how widening the bottom of pier foundations affects the seismic resistance, horizontal loading experiments were performed by installing two types of pier models in the ground, namely (i) a normal type with a leg diameter of $60 \mathrm{~mm}$ and (ii) a widened type with a width of $115 \mathrm{~mm}$. The main conclusions drawn are outlined below.

In a rigid frame subjected to horizontal load, tilted displacement occurs first, the vertical SR on the front side leg increases with increasing horizontal load, and the vertical SR on the back side leg decreases. The rotational center as a rigid frame is not at the center of the span but at a point closer to the front than the center of the span. The rotational center position differs between the normal type and the widened type. The widened type has a larger RRM arm length than the normal type because the rotational center is closer to the center of the span compared with that of the normal type. Therefore, compared to the normal type, the widened type has a larger RRM which at maximum is 1.28 times the RRM of the normal type. In design practice, such vertical SR distributions cannot be reproduced, and the RRM is underestimated.

When the amount of horizontal displacement with respect to the seismic coefficient is compared in terms of real scale, the widened type has $0.19-0.38$ times the horizontal displacement in the range of seismic coefficient from 0.4 to 0.6 compared with the normal type. Compared with the normal type, the widened type experiences less horizontal displacement, especially in the range of large seismic coefficient, and the widened type has remarkably high seismic resistance against the action of a massive earthquake. For vertical displacement, the widened type produces only $2 \%$ or less of the displacement of the normal type.

\section{ACKNOWLEDGMENTS}

The experiments were conducted with the help of Rie Yamaoka and Daisuke Shibata. This research was supported financially by JSPS KAKENHI Grant No. JP18K04324 and Oriental Shiraishi Co., Ltd.

\section{REFERENCES}

[1] T. Nagao, D. Shibata, "Experimental study of the lateral spreading pressure acting on a pile foundation during earthquakes", Engineering, Technology \& Applied Science Research, Vol. 9, No. 6, pp. 5021-5028, 2019

[2] K. Tokimatsu, Y. Asaka, "Effects of liquefaction-induced ground displacements on pile performance in the 1995 Hyogoken-Nambu Earthquake", Soils and Foundations, Vol. 38, No. Special, pp. 163-177, 1998

[3] PIANC, Seismic design guidelines for port structures, A.A. Balkema Publishers, 2001

[4] G. Mondal, D. C. Rai, "Performance of harbour structures in Andaman Islands during 2004 Sumatra earthquake", Engineering Structures, Vol. 30, pp. 174-182, 2008

[5] R. A. Green, S. M. Olson, R. Brady, B. R. Cox, G. J. Rix, E. Rathje, J. Bachhuber, J. French, S. Lasley, N. Martin, "Geotechnical aspects of failures at Port-au-Prince seaport during the 12 January 2010 Haiti earthquake", Earthquake Spectra, Vol. 27, No. Suppl. 1, pp. S43-S65, 2011

[6] T. Sugano, A. Nozu, E. Kohama, K. Shimosako, Y. Kikuchi, "Damage to coastal structures", Soils and Foundations, Vol. 54, No. 4, pp. 883901,2014 
[7] G. A. Athanasopoulos, G. C. Kechagias, D. Zekkos, A. Batilas, X. Karatzia, F. Lyrantzaki, A. Platis, "Lateral spreading of ports in the 2014 Cephalonia, Greece, earthquakes", Soil Dynamics and Earthquake Engineering, Vol. 128, Article ID 105874, 2020

[8] T. Nagao, P. Lu, "A simplified reliability estimation method for pilesupported wharf on the residual displacement by earthquake", Soil Dynamics and Earthquake Engineering, Vol. 129, Article ID 105904, 2020

[9] G. Li, R. Motamed, "Finite element modeling of soil-pile response subjected to liquefaction induced lateral spreading in a large-scale shake table experiment", Soil Dynamics and Earthquake Engineering, Vol. 92, pp. $573-584,2017$

[10] I. Towhata, Geotechnical earthquake engineering, Springer-Verlag, 2008

[11] M. A. Biot, "Bending of infinite beams on an elastic foundation", Journal of Applied Mechanics, Vol. 59, pp. A1-A7, 1937

[12] K. V. Terzaghi, "Evaluation of coefficient of subgrade reaction", Geotechnique, Vol. 5, No. 4, pp.297-326, 1955

[13] T. Yoshinaka, "Subgrade reaction coefficient and its correction based on the loading width", PWRI Report, Vol. 299, pp. 1-49, 1967 (in Japanese)

[14] R. Ziaie-Moayed, M. Janbaz, "Effective parameters on modulus of subgrade reaction in clayey soils", Journal of Applied Sciences, Vol. 9, pp. 4006-4012, 2009

[15] J. Lee, S. Jeong, "Experimental study of estimating the subgrade reaction modulus on jointed rock foundations", Rock Mechanics and Rock Engineering, Vol. 49, No. 6, pp. 2055-2064, 2016

[16] Japan Road Association, Specifications for highway bridges, Part 4, Substructures, Japan Road Association, 2016

[17] S. Iai, "Similitude for shaking table test on soil-structure-fluid model in $1 \mathrm{~g}$ gravitational field", Soil and Foundations, Vol. 29, No. 1, pp. 105118,1989 